\title{
COMMENT
}

\section{Response to the Comment by Moodley et al.}

\author{
Joan M. Bernhard ${ }^{1, *}$, Elisabeth Alve ${ }^{2}$, Andrew A. Reilly ${ }^{1}$ \\ 'Wadsworth Center, New York State Department of Health, Albany, New York 12201-0509, USA \\ ${ }^{2}$ Department of Geology, University of Oslo, PB 1047 Blindern, Oslo, Norway
}

The conclusions drawn by Alve \& Bernhard (1995) have been challenged in the foregoing comment by Moodley and co-authors. In the following we will address their 3 criticisms individually:

(1) 'Oxygen was not directly measured in the sediment' The primary aim of the experimental study was to study the vertical migratory response of benthic foraminifera to varied dissolved oxygen concentrations. By varying the oxygen concentration in waters bathing the 'experimental' mesocosm, the $\left[\mathrm{O}_{2}\right]$ in the sediment was also indirectly varied. Given solute diffusion laws, we know that the oxygen concentration in the sediments decreased when $\left[\mathrm{O}_{2}\right]$ was decreased in the overlying water However, Moodley et al.'s statement that 'in coastal sediments with relatively high organic carbon content, oxygen penetration depth is usually limited to a few $\mathrm{mm}^{\prime}$ is a vast over-generalization and we cannot confidently agree that the sediments in our experimental mesocosm were anoxic below a few mm depth. For example, it is commonly known that the activities of burrowing and tubicolous invertebrates significantly aerate subsurface sediments, often to considerable depths (e.g. Aller 1982, Meyers et al. 1987, Aller \& Aller 1992, Bakker \& Helder 1993) and the oxygenated haloes of such burrows are known to be colonized by foraminifera (Hohenegger et al. 1993). Such invertebrates were present in both mesocosms at the beginning of the experiment. While we noted that the majority of macrofauna died in our experimental mesocosm (p. 247), we must reiterate that not all the infaunal, burrowing organisms died. Furthermore, it is also known that at least some foraminiferal species create burrows (Severin et al. 1982) and therefore may aerate sediments themselves. Finally, Moodley et al. overlook the fact that the foraminifera migrated above the sediment-water interface

·E-mail: bernhard@wadsworth.org (i.e. on relict polychaete tubes) following exposure to dysoxic bottom-water conditions. Why should this response occur (along with the foraminiferal return to sediments after reaeration) if the foraminifera were not affected by dysoxia? Various alternative explanations were discussed and refuted by Alve \& Bernhard (1995) and will not be repeated here

(2) 'Their choice of reference level (depth above which $85 \%$ of the specimens $>63 \mu \mathrm{m}$ was found) is subjective' The use of a $63 \mu \mathrm{m}$ sieve size was carefully chosen as it is conventionally used by the vast majority of foraminiferal workers (see e.g. Moodley 1990 , Moodley et al. 1993). The $85 \%$ value was merely used to show schematically the foraminiferal response to our manipulations (i.e. Fig. 5 in Alve \& Bernhard 1995) and whether 80,85 , or $90 \%$ was used would not alter the actual vertical numerical density pattern

(3) 'Differences between control and experimental mesocosms were not significant given the limited replication'. Moodley et al. provide separate analyses for each sampling event 'since treatments ... differed for each event'. Such partitioning is inappropriate since it: (a) results in reduced power for testing oxygen; (b) discounts the portion of the protocol (e.g. nested core liners) developed to ensure sampling event homogeneity of subcores; and (c) eliminates the ability to test for time effects. We statistically evaluated the data using a different 2-stage non-partitioned analysis. The unnested stage tests treatment differences (of both oxygen concentration and time) against an error term estimated from both pseudo and non-pseudo replicates (i.e. between subcores and mesocosms; Table 1A). Thus, the analysis shows that oxygen and time both have a significant effect upon foraminiferal distributions ( $p=0.027$ and 0.031 , respectively). The observation that time has an effect is to be expected, since the study spanned 2 seasons when foraminiferal reproduction might occur. 
Table 1 (A) Unnested tests of treatment effects. (B) Nested tests of depth and its interactions with treatments

\begin{tabular}{|lrrrc|}
\hline Parameter & df & MS & $F$ & $p$ \\
\hline A. Unnested & & & & \\
Oxygen & 2 & 1.36 & 62.39 & 0.027 \\
Time & 4 & 1.12 & 51.48 & 0.031 \\
Error & 2 & 0.02 & & \\
B. Nested & & & & \\
Depth & 6 & 10.63 & 42.31 & $<0.0000001$ \\
Depth $\times$ Oxygen & 4 & 3.15 & 12.52 & $<0.0000001$ \\
Depth $\times$ Time & 4 & 0.79 & 3.13 & 0.019 \\
Error & 82 & 0.25 & & \\
\hline
\end{tabular}

The nested part of our statistical analysis tests for the effect of depth, including selected interactions with oxygen and time against variations arising from all other sources (Table $1 \mathrm{~B}$ ). This aspect of the analysis shows that variations in $\mathrm{O}_{2}$ concentration do not have the same effect at every depth. Rather, dysoxia causes increases in specimen abundance near $0.5 \mathrm{~cm}$ and decreases deeper in the core. This can be clearly seen at depths below $\sim 0.75 \mathrm{~cm}$ in Fig. $1 \mathrm{~B}$ where there is a one-to-one ordering of low to high abundance in inverse relationship to the bottom-water oxygen concentration. Additional evidence in this regard may be seen by comparing the abundances in the deeper parts of the subcores in Fig. 1B to those in Fig 1A. The analysis in Table 1 is well known in the statistical literature and can be studied either as repeated measures (Davidian \& Giltinan 1995), in which depth measurements are repeated on each core, or as a split plot analysis (Ostle \& Mensing 1975), with mesocosms as whole plots and subcore depths as split plots. The analysis (a) accounts for 105 degrees of freedom (including the implicit $1 \mathrm{df}$ mean parameter); (b) accounts for the number of data in Table 2 of Alve \& Bernhard; and (c) provides a good fit to the data (Fig. IA, B). We are at a loss to comprehend the analysis presented by Moodley et al., which contains 10191 degrees of freedom! Furthermore, Table 1 strongly supports the conclusions qualitatively reached by Alve \& Bernhard (1995) that oxygen has a major impact on depth distribution (Fig. 2).

Regarding Moodley et al.'s other comments, it is implicit that all the foraminiferal species survived our experimental treatment. Our observation of foraminiferal reproduction during exposure to depleted $\left[\mathrm{O}_{2}\right]$ is indeed interesting. However, the statement that our data is the 'first record of reproduction under dysoxic and suboxic/anoxic conditions' should read 'first record of foraminiferal reproduction under dysoxic con-

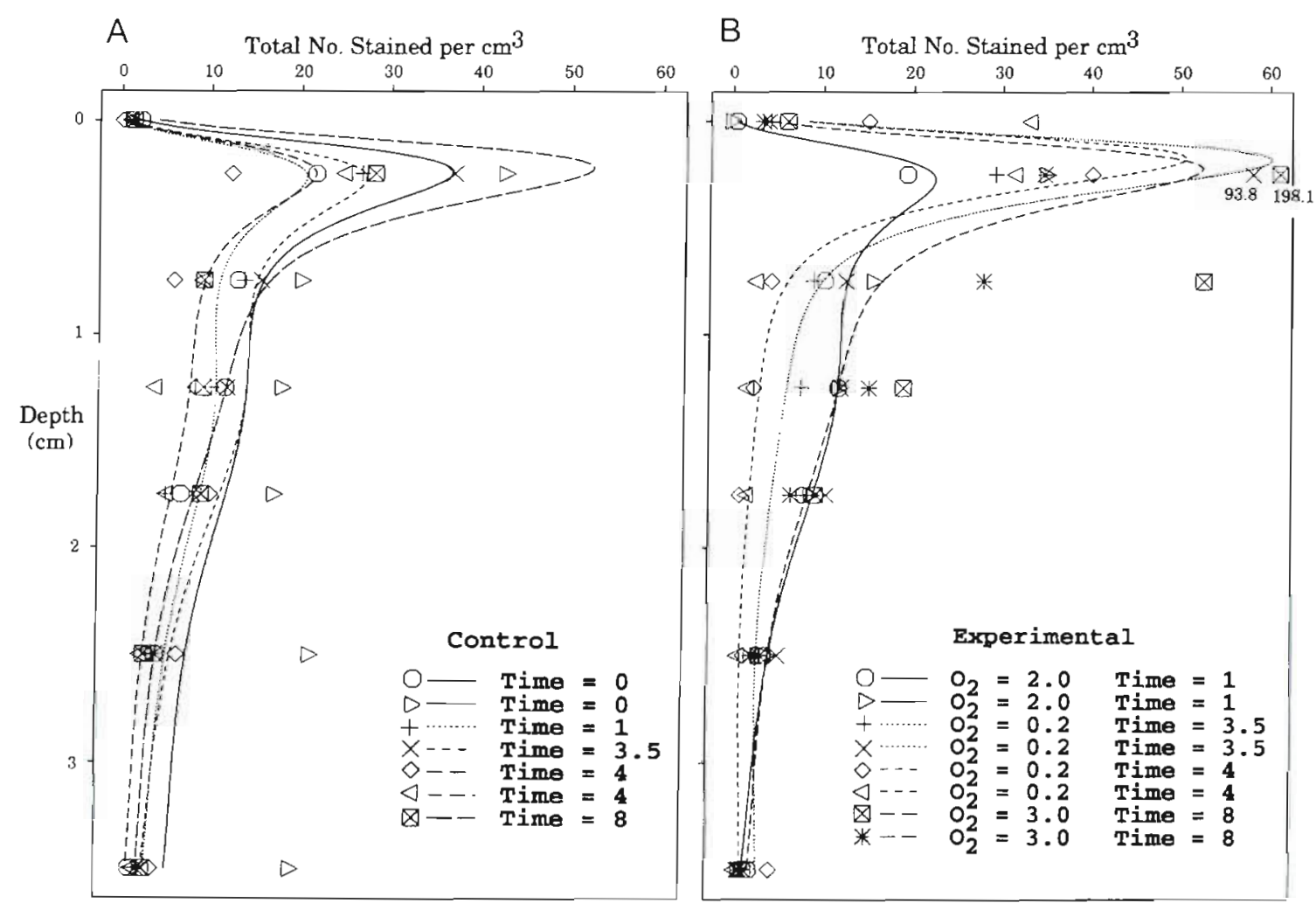

Fig. 1. Down-core foraminiferal numerical densities for (A) control and (B) expermental mesocosms with derived models for each treatment combination 


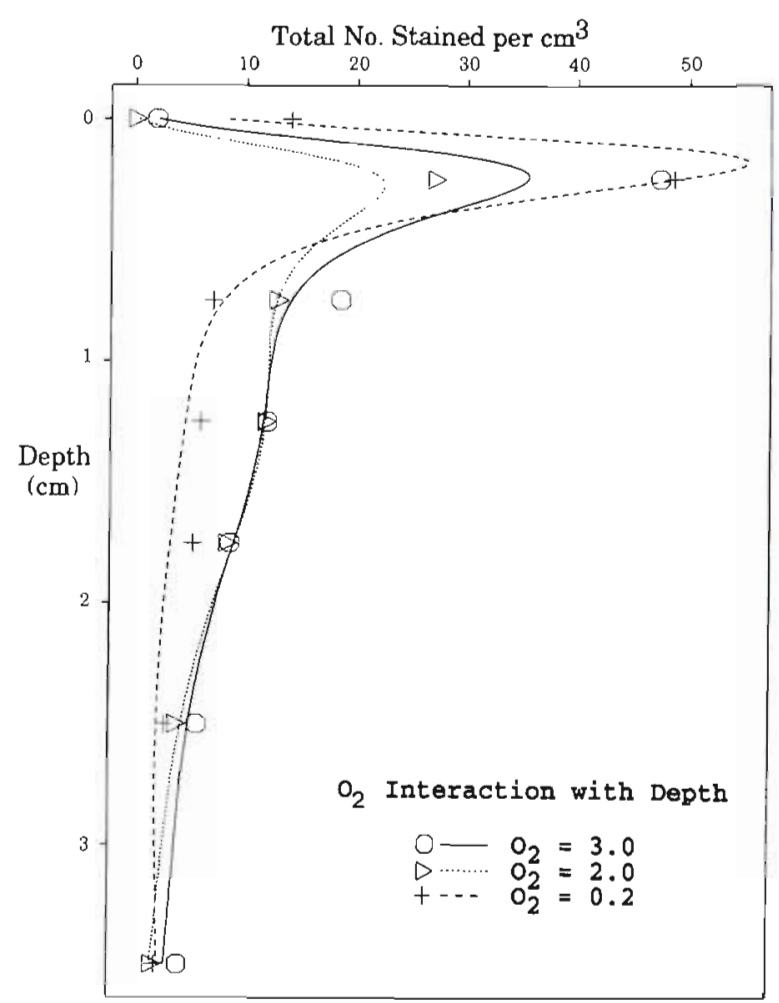

Fig. 2. Down-core foraminiferal abundances presented as a function of oxygen and depth. Note that the 2 higher oxygen concentrations yielded similar curves, with higher proportions of specimens downcore, while the curve for the lowest oxygen concentration shows considerably higher abundances near the sediment-water interface

ditions' since actual oxygen concentrations in the sediment pore waters are unknown. In addition, it is not valid for Moodley et al. to use our bottom water $\left[\mathrm{O}_{2}\right]$ to infer that the foraminifera survived anoxia. As noted above, it is not valid to assume dissolved oxygen was depleted to zero within the top few mm below the sediment-water interface.

In sum, we agree that certain foraminifera flourish when exposed to low oxygen concentrations. In fact, we have proposed in a number of papers that foraminifera are facultative anaerobes (e.g. Bernhard \& Reimers 1991, Bernhard 1993, 1996, Alve 1994, Bernhard \& Alve 1996). However, the study presented in Alve \& Bernhard (1995) was not designed to show anaerobiosis in foraminifera. Furthermore, we do not agree that the 'direct role of oxygen on the subsurface activity of benthic foraminifera may be grossly overestimated' Regardless of whether one considers forami- nifera to be obligate aerobes or facultative anaerobes (or even obligate anaerobes, for that matter), oxygen will have an effect upon their distribution.

We look forward to others replicating our experimental study with measurements of dissolved oxygen in the sedimentary pore waters.

\section{LITERATURE CITED}

Aller RC (1982) The effects of macrobenthos on chemical properties of marine sediment and overlying water. In: McCall PL, Tevesz MJS (eds) Animal-sediment relations. Plenum, New York, p 53-102

Aller RC. Aller JY (1992) Meiofauna and solute transport in marine muds. Limnol Oceanogr 37:1018-1033

Alve E (1994) Opportunistic Features of the foraminifera Stainforthia fusiformis (Williamson): evidence from Frierfjord, Norway. J Micropalaeontol 13:24

Alve E, Bernhard JM (1995) Vertical migratory response of benthic foraminifera to controlled oxygen concentrations in an experimental mesocosm. Mar Ecol Prog Ser 116:137-151

Bakker JF, Helder W (1993) Skagerrak (northeastern North Sea) oxygen microprofiles and porewater chemistry in sediments. Mar Geol 111:299-321

Bernhard JM (1993) Experimental and field evidence of Antarctic foraminiferal tolerance to anoxia and hydrogen sulfide. Mar Micropaleontol 20:203-213

Bernhard JM (1996) Microaerophilic and facultative anaerobic benthic foraminifera: a review of experimental and ultrastructural evidence. Rev Paléobiol 15:261-275

Bernhard JM, Alve E (1996) Survival, ATP pool, and ultrastructural characterization of benthic foraminifera from Drammensfjord (Norway): response to anoxia. Mar Micropaleontol 28:5-17

Bernhard JM, Reimers CE (1991) Benthic foraminiferal population fluctuations related to anoxia: Santa Barbara Basin. Biogeochemistry 15:127-149

Davidian M, Giltinan DM (1995) Nonlinear models for repeated measurement data. Chapman Hall, London, p 63-96

Hohenegger J, Piller W, Baal C (1993) Horizontal and vertical microdistribution of foraminifers in the shallow subtidal Gulf of Trieste, Northern Adriatic Sea. J Foraminiferal Res 23:79-101

Meyers MB, Fossing H, Powell EN (1987) Microdistribution of interstitial meiofauna, oxygen and sulfide gradients, and the tubes of macro-infauna. Mar Ecol Prog Ser 35:223-241

Moodley L (1990) Southern North Sea seafloor and subsurface distribution of living benthic foraminifera. Neth J Sea Res 27:57-71

Moodley L, Troelstra SR, Van Weering TCE (1993) Benthic foraminiferal response to environmental change in the Skagerrak, Northeastern North Sea. Sarsia 78:129-139

Ostle B, Mensing RW (1975) Statistics in research. The lowa State University Press, Ames, p 431-434

Severin KP, Culver SJ, Banpied C (1982) Burrows and trails produced by Quinqueloculina impressa Reuss, a benthic foraminifer, in fine-grained sediment. Sedimentology 29: $897-901$ 